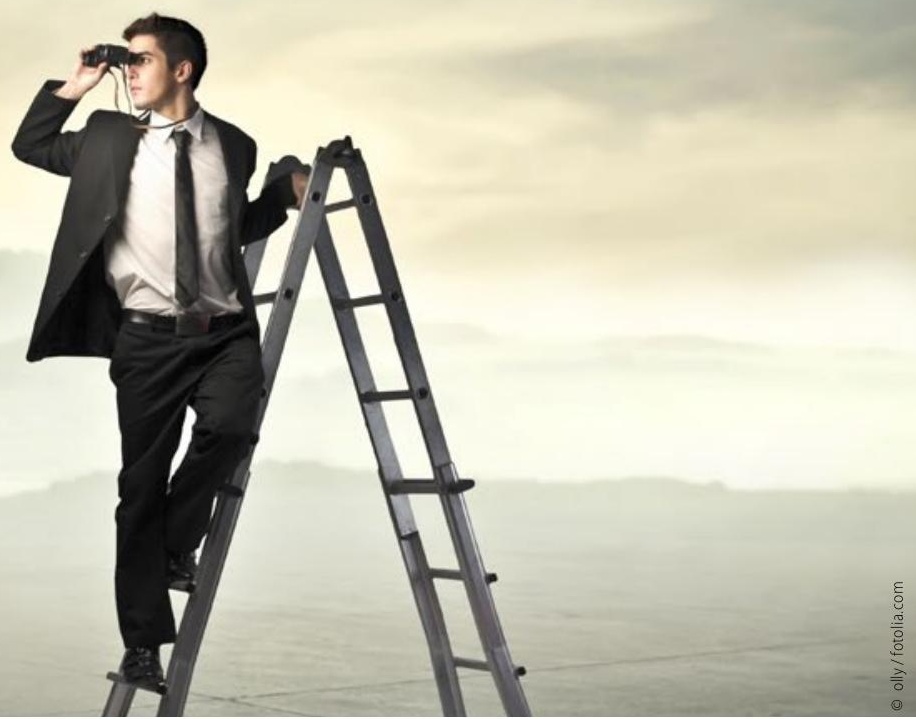

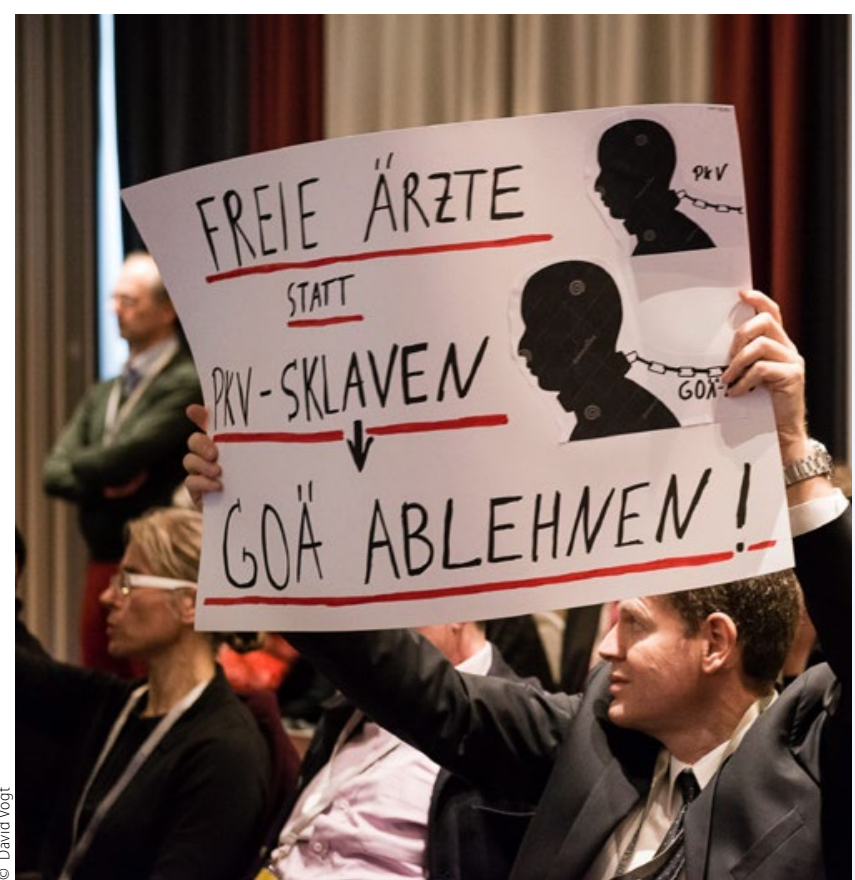

auch das Betreiben eines zahnärztlichen Labors, dem ein Zahnarzt immer wieder Arbeiten für die eigenen Patienten zuweist? Strafrechtler sind sich ziemlich einig, dass da jede Menge Zündstoff drinsteckt und gerade Zuweisungen und Laborbeteiligungen eine heikle Angelegenheit geworden sind. Und so hat ein Gesetz, das eigentlich eine Lücke im Strafgesetzbuch schließen und Rechtssicherheit bringen sollte, zu mehr Verunsicherung geführt, denn schon vor Inkrafttreten des Gesetzes haben Ärzte und Zahnärzte ja nicht im rechtsfreien Raum gelebt. Es gab und gibt Berufsordnungen, die sehr eindeutig sind, dazu das Sozialgesetzbuch und das Wettbewerbsrecht. Das neue Strafgesetz macht nichts einfacher oder klarer. Und so wird es auch noch lange bleiben, denn erst die Rechtsprechung wird in den nächsten Jahren klären, wie das Gesetz nun genau zu verstehen ist. Bis dahin gilt für Zahnärzte: Vorsicht bei vielen Formen der $\mathrm{Zu}$ sammenarbeit.

\section{Never-ending story: Die neue GOÄ}

Ein Thema hat die Ärzte- wie die Zahnärzteschaft gleich zu Beginn des Jahres besonders aufgewühlt - und ist im Verlauf von 2016 zu einem Dauerbrenner und Aufreger geworden: die Gebührenordnung für Ärzte (GOÄ). Nachdem die Details aus der neu verhandelten GOÄ bekannt geworden waren, schlugen die Wogen hoch. Intransparenz und nicht akzeptable Kompromisse wurden den Verhandlungsführern der Bundesärztekammer bei einem Außerordentlichen Ärztetag Ende Januar vorgeworfen. Doch am Ende stärkten die Delegierten ihren Verhandlungsführern doch den Rücken. Die wichtigsten Punkte der neuen GOÄ: Abgerechnet werden soll künftig in Euro, nicht mehr in Gebührenpunkten, und das nach dem „robusten Einfachsat““, der einem heutigen Steigerungssatz von etwa 2,4 entspricht. Gesteigert werden kann demnach dann nur noch in absoluten Ausnahmefällen auf das Doppelte des robusten Einfachsatzes. Entscheiden soll darüber eine Gemeinsame Kommission (GeKo). Beim Freien Verband Deutscher Zahnärzte wie auch bei einigen Ärzteverbänden, in denen hauptsächlich niedergelassene Kollegen organisiert sind, stießen die Ergebnisse auf strikte Ablehnung. Der FVDZ-Bundesvorsitzende Harald Schrader mahnte damals, wenn die neue GOÄ so verabschiedet werde, dann sei dies der Sündenfall. Für ein paar Euro würden die Grundfesten der Freiberuflichkeit - die freie Vereinbarung des Honorars - preisgegeben. Dass die GOÄ die Zahnärzteschaft nur in Randbereichen - nämlich vornehmlich bei der Abrechnung von Röntgenleistungen - betrifft, ließ der FVDZ nicht gelten: Eine neue GOÄ habe Signalwirkung auf die Gebührenordnung für Zahnärzte. Es folgten monatelange Diskussionen - bis zum Ärztetag im Mai. Dort wurden die GOÄ-Verhandlungen zunächst auf Eis gelegt. Vornehm ausgedrückt hieß es, der Ärztetag habe der Bundesärztekammer „Leitplanken für den weiteren Verhandlungsprozess mit dem Verband der Privaten Krankenversicherung eingezogen“. Klar war aber: In dieser Legislaturperiode wird es nichts mehr mit der neuen GOÄ. Inzwischen wird wieder verhandelt. Erst im November fand ein Spitzengespräch der Verbände statt. Ergebnis: Weder der robuste Einfachsatz noch die Geko sind vom Tisch. Die neue Verpackung der GOÄ wird vermutlich zum Ärztetag 2017 präsentiert. 